\title{
A cutting critique: transforming 'older' through cosmetic surgery
}

\author{
BRIDGET GARNHAM*
}

\begin{abstract}
This paper engages with a cultural politics of 'older'. At the centre of this politics are essentialist discourses of corporeal 'ageing' that limit and stigmatise the subjective experience of 'older'. Drawing together theoretical insights from Foucault's work on care of the self with data from in-depth interviews with 'older' people who have undergone cosmetic surgery and cosmetic surgery practitioners, this paper advances the proposition that cosmetic surgery can be re-imagined as an ethical practice of self-care. To critique the limitations imposed by 'natural ageing' through an ethic of 'ageing gracefully', the paper explores how older people who have undergone cosmetic surgery stylise the ethical experience of 'older' through active resistance of an 'elderly' identity. It argues that the practice of cosmetic surgery by 'older' people constitutes a cutting critique of the limits of 'older' and an experiment with the possibility of exceeding and ultimately transforming those limits.
\end{abstract}

KEY WORDS - older people, cosmetic surgery, ageing, Foucault, ethics, care of the self.

\section{Introduction}

This paper engages with a cultural politics of 'older'. Similar to the identity politics of other social positions, subjects take up this politics to 'reclaim ways of understanding their distinctiveness that challenge dominant oppressive characterizations' (Heyes 2009: n.p.). The cultural politics of 'older' therefore entails struggles around how 'older' identities are understood. Unlike the identity politics of gender, race or (dis)ability, however, 'older' has not yet been radically problematised or connected to material practices of social activism or resistance in academic discourses. As Gilleard and Higgs (2000: 3) assert, 'old age itself is not a site that is seriously contested or challenged. It remains a period of life that is excluded, marginalized or institutionalized'. This paper uses theoretical and empirical resources to contest and challenge

* School of Psychology, Social Work and Social Policy, University of South Australia, Adelaide, Australia. 
some of the prevailing ways in which 'older' is represented and understood to intervene in scholarly discourse and the cultural politics of 'older'.

The ontological problem that currently galvanises the cultural politics of 'older' emanates from essentialist discourses of the ageing body (see e.g. Cruikshank 2003; Gilleard and Higgs 2000; Gullette 2004; Hepworth 2003; Katz 1996; Powell 20o6) combined with neo-liberal governmental regulation of 'older' people through 'demographic and policy categories of risk and dependency' (Katz and Marshall 2003: 3; Tulle-Winton 2000; Warren 1998). In this discursive framework, 'older' is 'made evident in its bodily manifestations' (Tulle-Winton 2000: 78) and physical decline and decrepitude are established as essential properties of 'older people' (see e.g. Cruikshank 2003; Hepworth 2003; Powell 2006). These discourses intersect to constitute a prevailing ideation that works to stigmatise 'older' people and position 'older' as Other. This dominant and oppressive characterisation has deeply shaped the subjective experience of 'older' (Gilleard and Higgs 2011 ; Hurd Clarke and Griffin 2007; Smith et al. 2011).

An expanding literature within critical gerontology and ageing studies critiques the essentialism that currently inscribes the ontology of 'older' in academic and popular discourse (see e.g. Cruikshank 2003; Gilleard and Higgs 2000; Gullette 2004; Hepworth 2003; Katz 1996; Powell 2006). This literature focuses on 'cultures of ageing' and illuminates the social and cultural practices through which 'older' subjectivities are given meaning. However, in taking up this focus, this scholarship has re-established and re-privileged 'ageing' at the forefront of how 'older' is constituted and experienced. The extent of the conflation is such that the substantive focus of 'ageing studies' is 'older people' and so 'ageing' and 'older' operate as synonyms in this context. This reductive framework is problematic because the subjective experience of 'older' exceeds that of 'ageing'. It is essential to critical gerontology and ageing studies that lines of critique are developed that examine the limitations imposed on the field through discourses of ageing because these disciplines are a surface of emergence for discourses that constitute 'older'.

In terms of the cultural politics of 'older', critical attention needs to be granted to the ways in which older people themselves respond to the problematisation of 'older' and navigate prevailing discourses to constitute their subjectivity in ways that take up, resist or transgress prevailing ideation. Following Twigg (2004: 62), this paper argues that an empirical approach is needed that 'recognizes that personal struggles and experiences offer an important touchstone for academic theorizing' and that is 'grounded in the voices of those who are themselves subject to' constitution as 'older'. However, as Butler (2005: 7) reminds us, discourse establishes limits to the ability to give an account of the self since "there is no "I" that can fully stand 


\section{$135^{8}$ Bridget Garnham}

apart from the social conditions of its emergence'. Such complexity requires a nuanced reading, one that 'is necessarily beyond the stability of a humanist identity' and 'grounded in a politics marked by selves and ... inspired and engaged with the subjectivities enmeshed within our everyday lives' (Probyn 1993: 109). In other words, what is needed are ways to explore how 'older' people engage cultural practices to navigate, adapt or adopt cultural positions and thus constitute their subjective experience of 'older'.

This paper draws together theoretical and methodological resources from Foucault's later work on ethics, care of the self and critique (Foucault 1990 $a$, $1990 b, 1994 c$ ) with empirical data. The research that provides the empirical data features a case study research design used to explore how cosmetic surgery is engaged as a cultural practice by 'older' people to stylise identity. In-depth interviews were used to generate data from cosmetic surgery practitioners and 'older' people who have engaged in cosmetic surgery. The analysis presented in this paper identifies the limitations imposed by an ethic of 'ageing gracefully' and explores the stylisation of the ethical experience of 'older' through active resistance of an 'elderly' identity. In doing so, this paper develops the argument that the practice of cosmetic surgery by 'older' people constitutes a cutting critique of the limits of 'older' and an experiment with the possibility of exceeding and ultimately transforming those limits.

\section{Ethico-aethetics: stylising the self to transform subjectivity}

In his later work, Foucault $(1990 a, 1990 b)$ takes up the problem of ethical self-formation to problematise the dominant Western mode of ethics where the principle target is a 'hermeneutics of the subject' that produces essentialist conceptions of the subject. Through historical analyses of ancient Greek and Roman texts, Foucault's analyses explored 'how one ought to form oneself as an ethical subject' and 'the practices that enable him to transform his own mode of being' (Foucault 199ob: 26, 30). He defined these practices of self as 'the procedures, which no doubt exist in every civilization, offered or prescribed to individuals in order to determine their identity, maintain it, transform it in terms of a certain number of ends' (Foucault 1994f: 87). These practices were associated with a 'matrix of practical reason' (Foucault 1994g: 225) which Foucault (1991: 79) suggests 'inscribe themselves in practices' and are 'folded in' (Deleuze 1986) during processes of self-formation. These processes entail self-reflection, selfexamination, self-decipherment, self-transformation and so on and constitute a reflexive relation of self to self. The matrix of reason that Foucault (1990a, 1990b, 1994a, 1994c) locates in ancient Greek and Roman texts 
constitutes an aesthetic mode of ethics anchored in a stylistics of existence. This ethos was dominated by the principle of 'care of self' which meant continually 'working on' or 'being concerned with' the self (Foucault $1994 d)$. This work on the self was not an obligation imposed on the individual but rather associated with an active freedom. To engage in 'care of the self' was therefore to reflect upon oneself and freely cultivate oneself as an ethical subject by engaging in practices of self-care (Foucault 1994b).

Given that 'care of the self' entailed critical reflection, Rabinow (2003: 10) observes that it 'was also a form of critique, a critique of the self that entailed perpetual self examination'. Such a critique entails reflection upon how we are disciplined with respect to our identities and courses of action in order to test the limits of these forms of subjectivity and relations of power (Gabardi 2001). The practice of critique is thus, 'a means of contesting the identities constructed by experts, abstract systems and dominant groups' (Dean 1996: 214). Lloyd (1996: 25o, original emphasis) argues that 'self-fashioning, when allied to critique, can produce sites of contestation over the meanings and contours of identity, and over the ways in which certain practices are mobilized'. That sites of contestation over meaning can be generated by critique is in line with Foucault's conception of resistance and his proclamation that 'discourse is the power which is to be seized' (Foucault 1981: 211 ). Moreover, Lloyd is suggesting that through critical engagement, the rationality associated with practices of self can be negotiated or influenced. This latitude of movement, or slippage of meaning, is a strategic means for transforming the present.

Foucault briefly mentions the significance of this ethic of the self for understanding 'older'. He writes:

now that the care of the self must be practiced throughout life, but especially in adult life, now that the care of the self assumes its full dimensions and effects when one is fully adult, we see that the moment of the successful outcome and of the highest form of the care of the self, the moment of its reward, is precisely in old age. (Foucault 1994c: 108)

What Foucault is suggesting is that the benefits of having taken care of oneself throughout life are realised in old age. Through the continual practice of taking care of the self, Foucault (1994c: 110) suggests that it is possible to attain 'an ideal old age; an old age we produce, as it were, which we practice'. Given this conceptualisation of an ideal old age, Foucault suggests:

Old age should not be seen merely as a limit on life, any more than it is to be seen as a phase of diminished life. Old age should be considered, rather, as a goal, and as a positive goal of existence. We should strive towards old age and not resign ourselves to having it come upon us one day. Old age, with its own forms and values, should orient the whole course of life. (1994c: 109) 


\section{Bridget Garnham}

Whilst Foucault was writing about ancient Greek and Roman ethics, these ideas offer great potential for how we might begin to re-view 'older' in contemporary contexts to overcome the dominant negative connotations that emerge from discourses of ageing. His contention that practices of selfcare enable critical self-constitution is mobilised in this paper to suggest that older people who engage in cosmetic surgery do so in pursuit of an ethical stylisation of the experience of 'older'.

\section{Cosmetic surgery: a practice for stylising an 'older' self}

In popular media and some academic discourses, 'older' people who engage in cosmetic surgery are almost singularly considered to be 'denying ageing'. In much of the ageing studies literature, cosmetic surgery is understood as a means for resisting or denying being 'older'. Here 'older' is positioned at the centre of an ethical problematisation in which self-care practices are considered constitutive of an identity of 'staying young, choosing not to grow old' (Gilleard and Higgs 2000: 6o). Higgs et al. (2009: 699) state, for example, that 'anti-ageing medicine' including cosmetic surgery comprises practices of self-care that 'seek to overcome the ageing process or mask the signs of ageing'. These self-care practices generate ethical anxiety because they are considered to produce an appearance of 'non-agedness that further reinforces the undesirability and fear of old age' (Gilleard and Higgs 2000: 81). Such a reading positions cosmetic surgery as ethically problematic in that it is seen to reinforce and reproduce ageist beliefs and thus becomes understood as an ageist practice itself (Bayer 2005; Gilleard and Higgs 2000; Hey 2006; Hurd Clarke and Griffin 2007; Hurd Clarke, Repta and Griffin 2007).

The problem with anti-ageing interpretations are that they are premised upon essentialist conceptions of 'ageing' and 'problematically construct a natural, essential, authentic body' (Pitts-Taylor 2009: 121). In terms of the 'older' body, to borrow from Twigg (2004: 6o), '[e]ssentializing discourses in relation to the body need to be replaced by ones that recognize its nature as a social text, something that is both formed and given meaning within culture'. Conceptualisations of the body as a surface or plane of signification can generally be traced to Foucault who describes the body as 'the inscribed surface of events ... totally imprinted by history' (Foucault 1984: ${ }_{3}$ ). What he suggests is that the materiality and comportment of the body are shaped and given meaning through practices of discursive inscription. Through these practices, power is invested in the 'text' of the body and operates to shape the way in which it is 'read'. Given this theorisation of the body, the 'path to aging "naturally" is highly problematic' since 'If there is no natural 
body, then there is no natural way to age' (Twigg 2004: 63). If there is no natural way to age, then interpretations of cosmetic surgery as 'anti-ageing' are destabilised and questions are raised about what it means to look a particular age and attempts to look 'younger'. It becomes evident then, that cultural constructions of 'age' are imprinted on the body through a normative schema. Constituting the body as a canvas for inscription, the practice of cosmetic surgery opens up into possibilities for 'alternative modes of being and norms' (Gabardi 2001: 72) relating to the corporeal experience of 'older'. In relation to 'anti-ageing' practices, Cardona (2007: 224) suggests that corporeal enhancement technologies propose 'new standards of normality, success, and moral virtue' that provide 'new benchmarks of what a person should look and act like at certain age'. In other words, designing 'older' rather than denying ageing (Garnham 2013).

As a practice of body modification, cosmetic surgery is significant because the body is the nexus or site where 'forces of cultural reproduction, social structuation, and reflexivity' intersect to constitute the 'self' (Gabardi 2001: 88). As feminist scholars have argued, cosmetic surgery is therefore implicated in processes of becoming a subject and possible forms of subjectivity in Western society and culture (Fraser 2009; Heyes 2007; Jones 2008; Pitts-Taylor 2007). Read through Foucault's conceptualisation of care of self, whilst cosmetic surgery may inscribe and reinscribe normative forms of subjectivity, its practice might also be understood in terms of transforming the self. Adopting this position draws analytic attention to the ways in which agency, freedom and resistance are performed through the body using cosmetic surgery to stylise appearance, mode of being and experience of life in ways that challenge the oppressive and negative rendering of 'older'.

\section{Research design}

The research used to generate empirical data employed a case study approach. The significance of case studies, in relation to the methodological commitments of this paper, is beautifully captured by Heyes who writes:

the complex and sometimes contradictory local relations of power that form our ethical habitus are amenable to political interventions. Thus case studies are so important ... because they each happen at just such a point of rupture, crisis, or contradiction, and illustrate the workings of corporeal normalization at a level where transformative agency through local interventions is both possible and imaginable. (2007: 116$)$

This paper suggests that cosmetic surgery is a specific local intervention in which transformative agency is possible. Cosmetic surgery therefore provides a case study or, to follow Rabinow (2003), an 'exemplar' through which to 


\section{Bridget Garnham}

analyse points of rupture and contradiction in the ethical self-stylisation of 'older' subjectivities. This approach is 'Foucauldian' in the sense that many of Foucault's analyses of the subject were investigated by means of a case study or case history (Cousins and Hussain 1984). For example, Foucault's analyses of the ethical subject during particular historical periods were grounded in the study of sexuality as a privileged case (Florence 1994).

The boundaries that constitute 'older' people needed to be actively imposed to direct data generation. In Australia, like other developed nations, increasing longevity is driving the development of new categories and cultural understandings of age and a redefinition of existing categories. We are seeing, for example, the emergence of terms such as the 'young-old' and the 'old-old' to demarcate new demographic boundaries (Borowski and McDonald 2007). These new categories disrupt the normative lifespan and reveal the arbitrary limitations imposed by vertical containment in the horizontal structuring of society. The age group between 65 and 75 years is a historically 'new' demographic category sometimes termed the 'young-old' (e.g. Wenger 2003). The 'young-old' are considered to be a 'third age' in the lifecourse which is associated with the generation of new and modified cultural meaning (Gilleard and Higgs 2000; Higgs 1999; Twigg 2004). The age group $65^{-} 75$ years was therefore selected to provide an 'informationrich' (Patton 2002) demographic group for exploring new and modified cultural meanings and practices of self that constitute the experience of 'older'.

The lines that demarcate cosmetic surgery from other surgical and cosmetic procedures are at times unclear. However, in this study, cosmetic surgery was defined as a consumer-initiated procedure to improve appearance which is understood by same to constitute 'cosmetic surgery'.

Ethical clearance was obtained from the Human Research Ethics Committee at the University of South Australia and methods were embedded in the research design to ensure informed consent, voluntary participation and confidentiality. All names reported in this paper are pseudonyms. First names (e.g. James, Charlotte) designate 'older' people who have undergone cosmetic surgery whilst surnames (e.g. Dr Smith, Ms Taylor) designate practitioners in the cosmetic surgery industry who have experience working with 'older' patients.

Purposeful sampling strategies were used to deliberately select data sources that are information-rich (Patton 2002). A combination of cold calling and snowball sampling strategies (Patton 2002) were used to locate cosmetic surgeons who had experience with patients aged $65^{-75}$ years. Cosmetic surgeons also passed on information about the study to their patients who then contacted me if they wished to participate. 
T A B L E 1. Participants: 'older' people who have undergone cosmetic surgery

\begin{tabular}{|c|c|}
\hline Pseudonym & Profile \\
\hline Angela & $\begin{array}{l}\text { Angela is aged } 67 \text { and is retired but does volunteer work. At the time of the } \\
\text { interview she had been experiencing some health difficulties. She had been } \\
\text { recommended abdominoplasty but decided to have liposuction given the lower } \\
\text { risks and less invasive processes involved. The decision to have the procedure was } \\
\text { informed by both cosmetic and medical reasons for weight reduction but was } \\
\text { self-financed. }\end{array}$ \\
\hline Charlotte & $\begin{array}{l}\text { Charlotte is } 69 \text { years of age and lives with her retired partner. She works but their } \\
\text { main income is derived from investments. She has undergone cosmetic surgery a } \\
\text { number of times during her life including breast augmentation when she was } \\
\text { younger (and later removed), a facelift when she was in her forties, skin } \\
\text { resurfacing, liposuction and most recently (three months prior to the interview) } \\
\text { she had work done around her chin to reduce her jowls. }\end{array}$ \\
\hline Chloe & $\begin{array}{l}\text { Chloe is } 70 \text { years of age and lives with her partner of } 44 \text { years with whom she has } \\
\text { three children. She works full-time in her own business. Chloe had liposculture } \\
\text { of her abdomen. }\end{array}$ \\
\hline Chris & $\begin{array}{l}\text { Chris is aged } 70 \text { and is semi-retired. He had cosmetic surgery to lift the corners of } \\
\text { either side of his mouth and states that if he had the money he would get his } \\
\text { eyelids and stomach done. }\end{array}$ \\
\hline Emily & $\begin{array}{l}\text { Emily is } 68 \text { and lives alone. She is not particularly interested in activities related to } \\
\text { her appearance but underwent eye surgery (blepharoplasty), both her eyelid } \\
\text { and underneath her eyes. }\end{array}$ \\
\hline Heather & $\begin{array}{l}\text { Heather is aged } 69 \text { and lives alone. She works and has a chronic illness. Heather } \\
\text { sees a cosmetic physician to have laser treatment of her face and has chemical } \\
\text { peels regularly. }\end{array}$ \\
\hline Isabella & $\begin{array}{l}\text { Isabella is aged } 75 \text {, lives alone and is retired and receiving a pension. Over quite a } \\
\text { long period of time beginning with neck surgery, she had face peels, eyelid } \\
\text { surgery and liposuction. She had to work hard to save up the money for the } \\
\text { procedures. }\end{array}$ \\
\hline James & $\begin{array}{l}\text { James is aged } 72 \text { years old and has been retired for } 11 \text { years. He lives with his } \\
\text { partner of } 25 \text { years. James had two cosmetic procedures: surgery for } \\
\text { gynecomastia but this left his chest 'creased' and so he had another procedure } \\
\text { to improve the appearance of his chest. }\end{array}$ \\
\hline Mandy & $\begin{array}{l}\text { Mandy is } 66 \text { years of age and a widow of six years. Over a } 12 \text {-month period she had } \\
\text { a tummy tuck, breast reduction, liposuction of her thighs and mini facelift. }\end{array}$ \\
\hline Sophie & $\begin{array}{l}\text { Sophie is aged } 70 \text { and is a widow of } 12 \text { years. She has many complex health } \\
\text { difficulties and these are preventing her from having any further cosmetic } \\
\text { surgery. Sophie had a facelift when she was } 45 \text { and more recently has undergone } \\
\text { facial rejuvenation procedures including laser treatment, chemical peels and fat } \\
\text { transfer for her face and neck. }\end{array}$ \\
\hline Tom & $\begin{array}{l}\text { Tom is aged } 70 \text { and lives with his second wife. He is semi-retired in that he } \\
\text { undertakes paid work part-time but he has also remained involved in the } \\
\text { industry in which his career was based. He has undergone body contouring } \\
\text { procedures for his abdomen, jaw line and nose, and most recently a thread lift. }\end{array}$ \\
\hline
\end{tabular}


T A в L E 2. Participants: cosmetic surgery practitioners

\begin{tabular}{|c|c|}
\hline Pseudonym & Profile \\
\hline Dr Brown & $\begin{array}{l}\text { Dr Brown is a cosmetic physician with a general practice background that led to } \\
\text { an interest in surgery. He works in the area of cosmetic medicine and performs } \\
\text { a number of procedures but has a specialist area of expertise. }\end{array}$ \\
\hline Dr Cooper & $\begin{array}{l}\text { Dr Cooper is a plastic surgeon who works part-time in public hospital practice } \\
\text { and part-time in private practice. He performs both plastic and cosmetic } \\
\text { procedures. }\end{array}$ \\
\hline Ms Harris & $\begin{array}{l}\text { Ms Harris is a personal assistant to a plastic surgeon whose practice is comprised } \\
\text { of approximately } 60 \text { per cent cosmetic work encompassing a broad range of } \\
\text { procedures. Her role is to provide patients with quotes and information and } \\
\text { essentially operate as the conduit between patients and the surgeon unless a } \\
\text { direct consultation is required. }\end{array}$ \\
\hline Ms Robinson & $\begin{array}{l}\text { Ms Robinson owns/operates a beauty salon in the same building as a high-status } \\
\text { hairdressing salon that has the relaxed contemporary feel of a day spa. The } \\
\text { salon offers beauty treatments and therapies and some cosmetic medicine } \\
\text { including injection procedures. }\end{array}$ \\
\hline Dr Smith & $\begin{array}{l}\text { Dr Smith is a cosmetic physician with a general practice background. She } \\
\text { currently operates a private practice that focuses on cosmetic medicine and } \\
\text { minor surgical procedures. }\end{array}$ \\
\hline Ms Taylor & $\begin{array}{l}\text { Ms Taylor is the practice manager at a plastic surgery practice. The practice } \\
\text { includes multiple surgeons and covers a range of medical and surgical } \\
\text { cosmetic procedures and plastic surgery procedures. }\end{array}$ \\
\hline Ms Martin & $\begin{array}{l}\text { Ms Martin is a personal assistant to a plastic surgeon whose practice focuses on } \\
\text { cosmetic procedures. As part of her role she meets with patients to draw up } \\
\text { quotes, provide post-operative information and organises medical garments. }\end{array}$ \\
\hline Dr Watts & $\begin{array}{l}\text { Dr Watts is a cosmetic surgeon with a background in surgical and plastic surgery } \\
\text { training. His area of specialty is breast augmentation but he practises a range of } \\
\text { cosmetic procedures. }\end{array}$ \\
\hline Dr Williams & $\begin{array}{l}\text { Dr Williams is a cosmetic surgeon with a general surgery background in the } \\
\text { public hospital system. He specialises in body contouring procedures including } \\
\text { liposuction, liposculpture and breast surgeries. }\end{array}$ \\
\hline Dr Wilson & $\begin{array}{l}\text { Dr Wilson is a cosmetic surgeon with a background in cardiothoracic surgery } \\
\text { whose current cosmetic practice focuses on facial procedures. }\end{array}$ \\
\hline
\end{tabular}

The majority (eight) were female which reflects the gender imbalance amongst cosmetic surgery consumers. A diverse range of cosmetic procedures, including surgical and medical procedures, were represented in the sample with some participants having undergone multiple procedures. In the practitioner group there were an even number of males and females. Four participants worked in the industry of plastic surgery as practice staff, five were cosmetic surgeons or physicians, and one was a beauty therapist.

A semi-structured approach was taken to conducting the interviews (Kvale 1996; Patton 2002). Questions were generated from the topics: discourses that constitute understandings of cosmetic surgery practice, discourses that constitute subject positions in relation to 'older' and discourses that constitute subject positions in relation to older people who practise 
cosmetic surgery. Simultaneous data generation and analysis were carried out until data saturation was reached (Morse 1995).

The process of analysis began with descriptive and thematic stages according to the phases outlined by Braun and Clarke (2006). Thematic analysis was used to organise the data sets and identify patterns of regularity that might suggest the operation of discourse. The theoretical analysis undertaken in this study derives from both meditation on discourse and engagement with participant perspectives. However, the data sets do not form sites of analysis and nor do the participant's narratives form 'representative' perspectives or individual case studies. Moreover, this paper does not engage with a politics of 'voice'. Rather, the texts are sampled and problematised in terms of their articulation of prevailing discourses that inscribe the practice of cosmetic surgery undertaken by older people. The labour of meditation through which this problematisation was enacted entails practices of thinking and writing as methods of analysis (Deacon 2000; Richardson and St. Pierre 2005). Therefore, the analysis does not exist independent from this writing and is 'performed' in what is to follow. The analysis weaves discursive commentary with close data analysis and presentation in which connections are forged between theory and texts to explore how 'older' people engage cosmetic surgery as a practice of self-care to stylise an 'older' identity that exceeds limitations imposed by discourses of 'ageing'.

\section{The ethical principle of 'ageing gracefully'}

The notion of 'ageing gracefully' operates as an ethical principle that suggests 'older' people should accept 'natural' bodily ageing with a certain aesthetic style and grace. In our interview, when I asked James about the increasing numbers of 'older' people having cosmetic surgery he responded, 'Why they do that I don't know, why they can't be content to grow old gracefully and leave it at that I don't know'. When prompted to define what he meant by growing 'old gracefully' James replied, 'Just let things take their course - naturally'. Asked to elaborate, James stated:

We've often said, even a situation where people dye their hair when they get older, they've got an old wrinkled face, and dyed hair. It doesn't look right. An old wrinkled face should have grey hair, it's natural.

This association between 'ageing gracefully' and the 'natural' body is established in the literature (Fairhurst 1998; Twigg 2007). Surgical intervention to modify the 'older' body is therefore generally considered anathema to this notion (Hurd Clarke and Griffin 2007). The discursive 


\section{Bridget Garnham}

influence of the 'natural' body was evident in the data in terms of statements concerning the desired appearance of the post-surgical modified body. Fears of appearing 'plastic' or residual evidence of surgical intervention and thus being unable to 'pass' as natural were the outworking of this powerful influence.

When I asked Dr Smith what she thought growing old gracefully means she responded:

I don't think they know. I think they think that they'd like to look like Sophia Loren when they're 70 not realising that in fact Sophia Loren has had work done ... I mean how do you grow old gracefully?... I guess, you know, they'd like to be beautiful and serene and grow old. I mean that's not exactly the real world is it?

Dr Smith suggests that those people who aspire to 'ageing gracefully' and being 'beautiful and serene' do not realise Sophia Loren has had 'work done'. Her assertion 'I mean that's not exactly the real world is it?' suggests that 'ageing gracefully' entails body work rather than passive acceptance of 'natural' ageing. Ms Robinson explicitly associates 'ageing gracefully' with active engagement in practices to take care of the body:

the only ones who, I believe, really take care of their skin are the ones who have had a problem when they are young like acne or, you know, eczema or ... You know they're the ones who tend to age a lot more gracefully, I think because they haven't taken their skin for granted.

Similarly, Ms Taylor and Dr Wilson both suggest that 'older' people who 'look good' have engaged in practices to 'take care of themselves':

I look at my parents now and they don't look anything like 65 -year-olds. But occasionally you still see one that comes in and it's quite, yeah, a bit taken aback, you think 'God they're only 65 . That's really young. Why do they look so bad?' But socio-economic plays a lot to do with it I think. The less money you have, the less time you spend keeping yourself looking good. (Ms Taylor)

I mean a lot of these people in their fifties, sixties, you know, sixties, seventies, you look at them, have a look, just have a look at people generally. I mean not so much the ones in the old folks home who are frail and things like that, you know, but sometimes you look at them, you know, people are all fit and healthy at the beach, they take care of themselves and things like that... And why [do they look good]? A lot of these people they spent a lot of time taking care of themselves when they were younger and, you look at them, even now, they still look very good for their age, very fit for their age. So just to take care of themselves. (Dr Wilson)

The aesthetic style associated with 'ageing gracefully' may therefore entail taking care of the self through practices that cultivate the body rather than passive acceptance of 'natural' bodily ageing.

When I asked Dr Smith how she thought society at large views older people wanting to have cosmetic surgery she replied 'disgusting'. When asked to 
elaborate she replied, 'because we're hypocrites. And because fun and life and alcohol and sex and beauty and drugs are all only for young people. And I think it's an extension of that'. I asked whether she was suggesting that this was a form of ageism and she stated:

Absolutely. 'Why do they bother?' I think younger people view it like that. A lot of their peers would probably... I mean some people think, you know, 'Good on you, wish I could do it, don't have the courage, the money', the whatever. Some people would think that it's silly. I think the general opinion would be 'ick'. 'Why do they bother, they're old anyway.'

In terms of appearance and consumerism, Chris suggests that:

Just because people are older doesn't mean that they don't want to appear good in front of their peers. Older people get portrayed a bit too often as frumpy, lumpy and dumb and get ignored by major marketing chains, by market advertising campaigns. If you are over 28 forget it you are old, go away. Older people are too often regarded that way. But I don't think they think that way.

What this suggests is that it is not cosmetic surgery practice that is necessarily ageist but cultural topes such as 'graceful ageing' when this is taken to mean that, unlike other age groups, 'older' people should be proud of their 'natural' bodies and those who continue to engage in practices of self-care are shamed and denigrated.

The cultural politics suggested by 'ageing naturally' promotes acceptance and display of the 'naturally aged' body and through the ethical principle of 'ageing gracefully', the essentialist discourse of the 'natural' body operates as a limitation on the ethical stylisation of 'older'. Within this framework, engaging in practices such as cosmetic surgery are framed in terms of denial of ageing or attempts to look 'younger'. What this means is that 'standards of the 'natural' are seemingly functioning to establish normative limits of the acceptable' (Weiss and Kukla 2009: 124). The essentialism inherent to such an approach will fail to transform the system that positions 'older' bodies as undesirable. Rather, what is needed is a problematisation of 'youth' in aesthetics to imagine aesthetically desiring and desirable 'older' bodies. Hurd Clarke and Korotchenko's (2013) recent work on hair colour and the use of dyes in later life, for instance, reveals that the stylisation of hair colour is associated with aesthetic values that constitute white hair and particular varieties of grey hair as aesthetically desirable. In addition, this research showed that the practice of colouring ones hair was associated with the stylisation of a desirable 'older' identity. To develop this theme, this paper will now address, in depth and at face value, the contention that 'older' people engage with cosmetic surgery to stylise their embodied experience of 'older'. 


\section{Resistance of an 'elderly' identity: aesthetic stylisation of the 'older' self}

The suggestion that 'older' is constituted through aesthetic stylisation particularly emerged in my interviews with 'older' participants in the context of clothing style. Angela referred to the undesirability of dressing 'too young' in her statement that 'obviously you can't go like mutton dressed as lamb with little tights and little skimpy tops. That would be ridiculous wouldn't it?' However, others talked about the undesirability of dressing 'too old'. Emily, for instance, says 'I've got a friend who's 72 and she dresses older than what I do. She dresses like a grandmother'. When I asked her what she meant by this she responded:

Well nothing modern. Old fashioned. Like she'll look down on some of the things I wear because I like wearing nice casual clothes. What I think is nice anyway. Whereas, I mean in my day the older people wore everything that was dark. No colour. They were really drab and that's sort of how she is. And I don't want to be like that.

Here Emily suggests that dressing 'old' is to wear old-fashioned, dark, drab clothing as opposed to the nice casual modern clothes that she chooses for herself. Mandy specifically relates the cosmetic procedures she underwent, including tummy tuck, liposuction and breast reduction, to clothing choice. She states:

I wasn't wanting to turn the clock back to look 18 again. I just wanted to feel more comfortable in myself with clothes because when you are bigger it's really hard to buy clothes - modern clothes - you know they are all a bit frumpy.

Similarly, Chris suggests that, 'Older people who end up with stomachs and fat bums and stuff like that, they don't like the way they look, so in that way they'd like to trim down so they can fit better clothes'. Moreover, Chris explicitly links 'old' with clothing when he states 'Once you get above that [a size 14], you go from stylish clothing to old persons clothing. By that I mean the stretch jeans'. As this data illustrates, 'old' is constituted through aesthetic stylisation in ways that are considered 'drab', 'frumpy' and generally 'unstylish'.

Gilleard and Higgs (2000: 143) assert that 'people do not want to look old and unattractive'. However, this is more than just an aesthetic preference. When I asked Heather why she thought people in their sixties and seventies were deciding to have cosmetic surgery she responded:

Oh because, really you don't want me to tell you that do you? I tell you why. Because, you now become, when you get to my age, an invisible person. Look I'm lucky; I know that I'm still not ugly. But I know that a lot of older women are just bypassed and I have seen it and I notice it. 
She went on to talk about customer service in shops and a social experiment conducted by the BBC where they:

dressed a young women as an old woman and got her to go into a shop there was no attention paid to her, she didn't get the service, the guy didn't smile at her. But when she took off all that old garbage and she went back into the shop, the guy, you know she was showing a bit of cleavage and walked in, and the guy was over her to help her.

She concluded that 'if you're not fuckable - desirable - then they're not even going to talk to you so that's why'. For Heather personally, appearance is important because she states, 'I still want to be taken seriously as a person so I do not want to look old and drab. What I said to you before about being overlooked as an older person'. More than aesthetics, an 'old and drab' appearance works to socially and culturally position individuals as 'elderly':

Well people are accepting that I don't look old. No-one treats me old. I am talking about people who are sometimes 40 years younger than me. I am not treated as an old person. My husband is, people leap up and offer him a seat and it makes him so mad. (Charlotte)

People treat them differently. I think people treat them like they're perhaps going a bit senile. (Dr Smith)

So if they act younger, look younger then they'll treat them in one way and if they act really old and look really old then they'll be more helpful... (Ms Taylor)

An old and unattractive appearance is therefore not only aesthetically displeasing but entails undesirable social and cultural differentiation in terms of an 'elderly identity'. This speaks to 'a relational self where intersubjectivity becomes central-a self that acknowledges and is constituted by difference and the Other' (Besley and Peters 2007: 20).

Dr Wilson captures this notion and suggests that being positioned as 'Other', in this case 'elderly', is like being in the 'wrong costume' when he states:

you know it's like Shakespeare says that, you know, 'We are all actors on a stage'. Well it's the same thing, you see. It's like, you know, it's like what mask you have on your face, you know and you play that role and when you suddenly can't play that role convincingly, how would you feel? It's like you're going on stage to play Hamlet but you look like somebody else, you're in the wrong costume and you have to play that. It's not going to be right is it?

Many of the 'older' participants interviewed explicitly positioned themselves as 'not old'. However, this does not necessarily mean that they are denying or resisting chronological age or that they are 'old'. Rather, these statements can be interpreted as a desire to exceed the boundaries that seek to constrain them, regulate their conduct and determine the nature of their 


\section{Bridget Garnham}

interpersonal relations. As Gilleard and Higgs (2000) assert, 'older' people are happy to age but not be 'aged'. The stylisation of 'older' using practices to fashion the appearance of the body is therefore deployed in struggles around subjectivity to challenge, resist and subvert forms of subjectivity connected to being 'aged'.

\section{Stylisation of an active 'older' self and lifestyle}

By far the most commonly used adjective in the texts generated for this study to describe 'older' in terms of self and lifestyle was 'active'. Almost all of the 'older' participants in this study described themselves and their lives as 'active'. For Tom being active means:

There is nothing I can't do. I still go ice-skating with the grandkids. I do indoor bowls two nights a week. I dance to every bit of music, I am a crazy dancer. I love dancing.

Tom, Isabella and Mandy consider an active lifestyle to be a life where you 'make the most out of it'.

In our interviews Charlotte and Chloe both suggested that an active 'older' lifestyle is linked to cosmetic surgery and wealth:

People in their sixties if they decide to have facelifts, they want to and they don't see their age, they see it as an improvement for their time in life and they still have plenty of things they're planning to do - they are going to travel and just live a life. It's not old in their eyes. You have got to get to that age to realise that it is much more fun, life is so much better as you get older, because you own your possessions; you have a choice of whether you want to get more or not. (Charlotte)

Well we are fortunate that 60 - and 70 -year-olds have got to that age feeling good, still living good lifestyles, busy lifestyles, still earning money, able to take trips overseas. Most of us our children have left home and are standing on their own feet, therefore we are financially quite independent and we don't hesitate to spend money and enjoy the years that we have. I think we have quite high expectations, we are not ready to sit in the rocking chair on the veranda by any means, we have things to do and places to go, but we want to look good and if finances are there, yes cosmetic surgery is part of it. (Chloe)

As these extracts demonstrate, Charlotte and Chloe see 'older' as a time of freedom from financial struggle and being able to enjoy the consumption of commodities. Chris also reflects that money is an important factor in active lifestyles and suggests that such lifestyles may not be available to 'pensioners' relying on social retirement schemes for income. Whilst a certain amount of disposable income is needed to engage in the practice of cosmetic surgery and fashion active lifestyles, the 'older' participants interviewed for this study came from a range of socio-economic positions. Whilst Mandy revealed money was not a consideration in her decision to have cosmetic surgery, 
Isabella spoke of her careful saving plan whereby she put aside small sums until she had saved enough for her procedure.

The 'cultural habitat' (Gill 2008), comprising employment, wealth, leisure activities, health, social and romantic relationships, is associated with the 'young-old' or 'third age' subject ( see e.g. Featherstone 1995; Gilleard and Higgs 2000; Katz and Laliberte-Rudman 2005; Katz and Marshall 2003; Powell 2006). James specifically connects being 'active' with the 'young-old' in his statement:

You can hardly classify yourself as young-old if you weren't active, could you? If you were $65^{-75}$ and you weren't active and you just sat around watching television and reading the newspaper and couldn't go out and do the garden or couldn't do jobs around the house you could hardly be classed as young-old could you? If you weren't able to do things, you wouldn't feel young. If you couldn't do things. I feel as if I am alright because I can still do things. I'm active.

In the following statement Chloe suggests the importance of lifestyle to the new cultural constitution of the 'young-old':

I don't think today's 7o-year-old is anything like the last 20 years ago or my parent's age. Sadly my mother didn't live beyond 62 but I think I am probably a younger 70-year-old than she would have been and I think the next generation will be extremely young at 70 because we are lucky we can maintain a healthy, fit lifestyle. As long as you don't get any dreaded disease or health problems, no reason we shouldn't go on for many more years. It is the maintenance! - the vitamins, the good food and I think mental health is important. Your mental attitude to everything is important.

As this extract suggests, maintaining a 'healthy, fit lifestyle' and 'mental attitude' is a condition of possibility for the constitution of the 'active' 'youngold'. Chloe links being 'active' with physical and mental health in her statement that:

I think because there are a lot of us now who are active, you look into the political world, the arts world, the music world, the business world. There are plenty of $60^{-}-65^{-}$, 70-year-olds still doing a great job with a lot to offer. These days I don't think the older generation hits 60 and thinks I must retire now, they are happy to keep working for various reasons but generally they feel good, if they are physically fit, mentally alert why stop? I think we are getting more respect because people see how capable, and I am not talking me personally, but generally in the bigger world there are so many at that age group still doing a fantastic job and a lot to offer.

Similarly, Angela suggests, 'so if you can keep the right weight, eat right and whatever then you can participate in a lot more things and stay active. Not die in a heap when you get to 70 . I am trying to do that'.

Despite the association between active lifestyles and health, good health was not a precondition for Sophie's experience of engaging in cosmetic surgery and constitution of an 'active' and 'young-old' subjectivity. 


\section{Bridget Garnham}

Sophie talked about having a near-death experience, a chronic condition, cancer and other health problems. At the time of the interview Sophie had decided not to undergo any further cosmetic procedures because her postsurgical recovery was becoming too difficult. However, prior to that, her health difficulties had not prevented her from having cosmetic procedures to enhance her appearance and 'feel better'. From these excerpts it is possible to say that rather than good health per se, it is engaging in practices to take care of oneself that is the condition of possibility that enables the constitution of an active lifestyle and the 'young-old' subject.

As cultural theorists in ageing studies have observed, the social and cultural constitution of the 'third ager' or 'young-old' has occurred through neoliberal and consumer discourses of active, successful, productive and healthy ageing (see e.g. Featherstone 1995; Gilleard and Higgs 2000; Katz and Laliberte-Rudman 2005; Katz and Marshall 2003; Powell 2006). As Katz (2005: 121 ) notes in his paper 'Busy Bodies', 'the notion of activity, a recurring motif in popular treatises on longevity since the Enlightenment, today serves as an antidote to pessimistic stereotypes of decline and dependency'. He goes on to argue that modern gerontology and associated health-care professions have seized on 'activity' as an ethical keyword to generate 'critical intersections between activity and regimens of care and lifestyle with a focus on the management of everyday life in old age'. 'Activity' thus 'marks an alliance between political and personal aspirations' (Cardona 2008) for 'positive, healthy, independent lives' (Katz 2005: 126). 'Older' subjectivities styled in relation to principles of being 'active' thus form at the intersection of relations of power and practices of self-care.

The problem, Katz (2005: 122) argues, is that social welfare policies are eroded in favour of 'neoliberal policies and market-driven programmes to 'empower' older individuals to be active in order to avoid the stigma and risks of dependency'. However, these policies fail to address the ways in which socio-economic position, gender and race affect the capacity of individuals to engage in practices of self-care and exclude possibilities of 'successful ageing' that are not premised on individual's ability to be physically and financially independent. 'Ageing well' thus becomes an individual responsibility within a context of structural constraint (Katz and Laliberte-Rudman 2005 ).

'Deploying a catch-all cry against neoliberalism and governmentality' to show how the 'older' body is 'rendered fodder for the machine that produces "better" citizens' would be, to borrow from Probyn (2008: 402-3), 'the spectacular analysis of the obvious'. In terms of fat and feminism, she argues that whilst such critique proves an obvious point, such scholarship does little to intervene. Like Probyn's critique of feminism, the ageing studies 
scholarship described is informed by a narrow reading of Foucault. This means that the insights derived from this work are methodologically and politically limited because they fail to acknowledge agency in terms of the ways 'older' subjectivities are navigated, adapted, adopted and constituted by the subject. The new 'young-old' subject, to parallel Gill's (20o8: 438-9) argument in relation to post-feminist femininity, 'highlights the way in which power and ideology operate through the construction of subjects, not through top-down imposition but through negotiation, mediation, resistance and articulation'. Rather than a governmental practice conditioned by discourses of 'active ageing', cosmetic surgery can be read as an ethical practice of critique.

\section{Exceeding the boundaries of 'older': cosmetic surgery as an ethical practice of critique}

Through critique of the ethical principle of 'ageing gracefully', this paper problematised 'natural ageing' in relation to 'older' people. As Tulle (2008: 7) suggests, the problem lies with age acting as a limiting 'structure guiding our social location and our dispositions'. As Dr Wilson observes:

age is a number and it's a number that society has created to, control, you know, maybe for ranking, whatever it is but I think, you know, in the 21 st century people are living longer and longer ... I don't know, age is a number. Age is truly a number, you know.

Dr Wilson might have said that 'age is only a number' but his statement still suggests that chronological age does not confer an essentialist nature to 'older'. Interestingly, Dr Wilson states 'but I honestly, I don't judge people by their age. I don't look at the numeric numbers. I look at their phenotype age'. What Dr Wilson is suggesting by 'phenotype' age implies a judgement based on physical appearance and self-expression and thus the possibility of exceeding limitations imposed by chronological age through self-stylisation.

Many of the interviewees suggested that 'age is just a number' and 'old' is a state of mind. Heather, for instance, proclaims:

Look I used to nurse with people who were 16 going on 100 who were boring farts and I nursed someone who was 85 going on 16 . It's a number. It's all to do with the mind and keeping the body active.

Similarly, Mandy states:

When you say an age $6_{5}$ or more people think of you as being a senior citizen, you are old. But really your age is just a number and some people are younger at $6_{5}$ than others. 


\section{Bridget Garnham}

Dr Smith described 'old' as a state of mind unconnected to chronological age:

I mean I've got patients who are old at 45 and I've got patients who are young at 90. Mainly, often it's a mental attitude, I think. You know, if someone's wanting to be interested in life and doing things and out and about and, you know, interacting with whatever club and having some hobbies and sport or whatever, then they're younger than a person who sits at home and does nothing.

In addition, the data generated for this study suggests that 'older people' are challenging normative expectations in relation to chronological age and transforming what it means to be 'older'. In his interview Chris states:

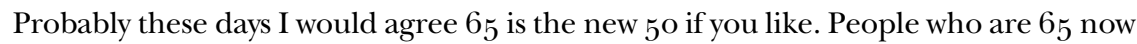
are probably more able to relate to $5^{\mathrm{o}-y e a r-o l d s}$ and their music and what they like to see and what they like to do than maybe 65 -years-olds did 25 years ago. There is better health in older people now than there used to be. The days of you working until you were 60 , and dead by the time you were 63 , well now you work until you are 70 and you are not dead until you are 83 . I don't know how you calculate that, but I don't consider myself an old 7o-year-old. I consider myself an under 6o-year-old because of what I like to do which is in part what I have been doing all my life. I don't want to sit around playing cards or snap or bowling and stuff like that. I like jumping out of aeroplanes, once!

Chris' suggestion that ' 65 is the new $5^{0}$ ' reveals a contemporary shift in Western cultures of 'older'. As his statement illustrates, this shift is partly attributable to increasing longevity and accompanying social changes. However, the choice to skydive rather than play cards or bowls speaks to 'older' in terms of new possibilities and practices.

Ms Taylor and Ms Robinson talked about possibilities and practices concerning 'older' in the following statements:

I think over the last, probably 20 years, there's been more emphasis on keeping yourself looking good and, you know, keeping yourself fit and eating healthy and all those sorts of things, not going grey when you're 6o which is what my grandparents generation did. Whereas my parents generation don't seem to do that. They're very active and doing things still. I think that there will be more and more facelifts. (Ms Taylor)

I think it's, well they're a lot fitter, I think than my grandparents would have been because they have been taking care of the outside which takes care of the inside, the spirit, which is what nurtures us really and our wellbeing. In essence. If your spirit's good then physically we're good, aren't we? Because you can go out and do that dance, you can go out and you know, do salsa dancing at 7o. You are able to do it. Because you feel good about yourself. (Ms Robinson)

As these excerpts suggests, these new possibilities and practices are connected to an 'active' lifestyle and regimen of self-care. 
Charlotte, Mandy and Angela express a critical attitude about age in terms of the rhetorical question 'why not?' when asked about their decisions to have cosmetic surgery:

Why not? I think it is an attitude also. Why not? (Charlotte)

You start off by doing it because you look in the mirror and you might be seeing something that could be tighter and you think why not do it? (Mandy)

If you can afford cosmetic surgery, then why not? (Angela)

In his work conceptualising critique as an ethical practice, Foucault (1997: 32) considers the act of voluntary insubordination a virtue. For Foucault (1997: 28), this entails a 'critical attitude' and 'an act of defiance' in relation to mechanisms of subjection that operate to render individuals intelligible and govern their conduct. The question 'why not?' is an act of defiance that exemplifies what Foucault meant by voluntary insubordination and critique. Such a critique entails reflection on how we are disciplined with respect to our identities and courses of action in order to test the limits of these forms of subjectivity and relations of power (Gabardi 2001). For 'older' people who engage in cosmetic surgery, this attitude can be interpreted as 'testing the limits' of 'older' to explore the possibility of transgressing and ultimately transforming those limits.

\section{Conclusion}

Using Foucault's work on ethics to interpret empirical data, this paper focused on how the practice of cosmetic surgery is reflexively mobilised as a critique of the limits of 'older' subjectivities. It establishes that the ethical principle of 'ageing gracefully' is connected to the stylisation of 'older'. This ethic is premised on the 'natural body'. However, this paper suggests that the aesthetic style and grace associated with 'ageing gracefully' entails taking care of the self through practices that cultivate the body rather than passive acceptance of 'natural' ageing. This paper explored the stylisation of the ethical experience of 'older' and active resistance of an 'elderly' identity. In doing so, it developed the argument that the practice of cosmetic surgery by 'older' people constitutes a cutting critique of the limits of 'older'.

Body modification practices such as cosmetic surgery speak to an aesthetic ethics. In terms of older people who engage in cosmetic surgery, this ethics is associated with an art of 'older' rather than an essential nature. Through ethical practices of self-care and self-stylisation of active selves and lifestyles, 'older' people are 'challenging dominant discursive representations of old age as burden and decline and reasserting old age as opportunity and choice' (Cardona 2008: 480). In terms of his own politics and practices, 


\section{Bridget Garnham}

Foucault suggests 'we don't have to discover that we are homosexuals... Rather, we have to create a gay life. To become' (1994e.163). Certainly, as we grow older we don't have to discover that we are 'old' or 'elderly' but rather as Foucault suggests we have to create an 'older' life. With its own 'forms and values' 'older' might be reconceptualised as a way of being characteristic of a life well lived. Becoming 'older' would thus form a positive goal of existence to be strived towards and reflexively stylised.

\section{Acknowledgements}

I thank the 'older' participants and pilot study volunteer who shared their time, perspectives and personal experiences and also the cosmetic surgery practitioners whose invaluable support and assistance in participant recruitment helped make this study possible. I would especially like to acknowledge and thank Dr Vicki Crowley for support, critical engagement and scholarly inspiration throughout this research.

\section{References}

Bayer, K. 2005. Cosmetic surgery and cosmetics: redefining the appearance of age. Generations, 29, 3, 13-18.

Besley, T. A. C. and Peters, M. A. 2007. Subjectivity and Truth: Foucault, Education and the Culture of the Self. Peter Lang Publishing, New York.

Borowski, A. and McDonald, P. 2007. The dimensions and implications of Australian population ageing. In Borowski, A., Encel, S. and Ozanne, E. (eds), Longevity and Social Change in Australia. University of New South Wales Press, Sydney, $15^{-39}$.

Braun, V. and Clarke, V. 2006. Using thematic analysis in psychology. Qualitative Research in Psychology, 3, 2, 77-101.

Butler, J. 2005. Giving an Account of Oneself. Fordham University Press, New York.

Cardona, B. 2007. 'Anti-aging medicine' and the cultural context of aging in Australia. Annals of the New York Academy of Sciences, 1 1 14, $216-29$.

Cardona, B. 2008. 'Healthy Ageing' policies and anti-ageing ideologies and practices: on the exercise of responsibility. Medicine, Health Care and Philosophy, 11, 4, 475-83.

Cousins, M. and Hussain, A. 1984. Michel Foucault. Macmillan, London.

Cruikshank, M. 2003. Learning to Be Old: Gender, Culture and Aging. Rowman \& Littlefield, Boston.

Deacon, R. 2000. Theory as practice: Foucault's concept of problematization. Telos, $118,127-42$.

Dean, M. 1996. Foucault, government and the enfolding of authority. In Barry, A., Osborne, T. and Rose, N. (eds), Foucault and Political Reason: Liberalism, Neoliberalism and Rationalities of Government. University of Chicago Press, Chicago, 209-29.

Deleuze, G. 1986. Foucault. University of Minnesota Press, Minneapolis, Minnesota.

Fairhurst, E. 1998. 'Growing old gracefully' as opposed to 'mutton dressed as lamb': the social construction of recognising older women. In Nettleton, S. and Watson, J. (eds), The Body in Everyday Life. Routledge, London, 258-75.

Featherstone, M. 1995. Post-bodies, aging and virtual reality. In Featherstone, M. and Wernick, A. (eds), Images of Aging: Cultural Representations of Later Life. Routledge, London, 227-44. 
Florence, M. 1994. Foucault. In Faubion, J. D. (ed.), Michel Foucault: Aesthetics, Method and Epistemology. The New Press, New York, 459-64.

Foucault, M. 1981. The order of discourse. In Young, R. (ed.), Untying the Text: A Post-structuralist Reader. Routledge \& Kegan Paul, Boston, $4^{8-78 .}$

Foucault, M. 1984. Nietzsche, genealogy, history. In Rabinow, P. (ed.), The Foucault Reader: An Introduction to Foucault's Thought. Random House, New York, 76-1oo.

Foucault, M. 1990a. The Care of the Self: The History of Sexuality. Volume 3, Penguin Books, London.

Foucault, M. 199ob. The Use of Pleasure: The History of Sexuality. Volume 2, Vintage Books, New York.

Foucault, M. 1991. Questions of method. In Burchell, G., Gordon, C. and Miller, P. (eds), The Foucault Effect: Studies in Governmentality. Harvester Wheatsheaf, Hemel Hempstead, UK, 73-86.

Foucault, M. 1994a. The ethic of care for the self as a practice of freedom. In Bernauer, J. and Rasmussen, D. (eds), The Final Foucault. The MIT Press, Cambridge, Massachusetts, 1-20.

Foucault, M. 1994 $b$. The ethics of the concern with the self as a practice of freedom. In Rabinow, P. (ed.), Michel Foucault: Ethics, Subjectivity and Truth. The New Press, New York, 281-302.

Foucault, M. 1994c. Nietzsche, Freud, Marx. In Rabinow, P. (ed.), Michel Foucault: Ethics, Subjectivity and Truth. The New Press, New York, 269-78.

Foucault, M. 1994d. On the genealogy of ethics: an overview of a work in progress. In Rabinow, P. (ed.), Michel Foucault: Ethics, Subjectivity and Truth. The New Press, New York, 253-80.

Foucault, M. 1994e. Sex, power and the politics of identity. In Rabinow, P. (ed.), Michel Foucault: Ethics, Subjectivity and Truth. The New Press, New York, 163-74.

Foucault, M. 1994f. Subjectivity and truth. In Rabinow, P. (ed.), Michel Foucault: Ethics, Subjectivity and Truth. The New Press, New York, 87-92.

Foucault, M. 1994g. Technologies of the self. In Rabinow, P. (ed.), Michel Foucault: Ethics, Subjectivity and Truth. The New Press, New York, 223-52.

Foucault, M. 1997. What is critique? In Lotringer, S. and Hochroth, L. (eds), The Politics of Truth. The MIT Press, Cambridge, Massachusetts, 23-82.

Fraser, S. 2009. Agency made over? Cosmetic surgery and femininity in women's magazines and makeover television. In Heyes, C. and Jones, M. (eds), Cosmetic Surgery: A Feminist Primer. Ashgate Publishing, Farnham, UK, 99-1 16.

Gabardi, W. 2001. Negotiating Postmodernism. University of Minnesota Press, Minneapolis, Minnesota.

Garnham, B. 2013. Designing 'older' rather than denying ageing: problematizing anti-ageing discourse in relation to cosmetic surgery undertaken by older people. Journal of Aging Studies, 27, 38-46.

Gill, R. 2008. Culture and subjectivity in neoliberal and postfeminist times. Subjectivity, 25, 432-45.

Gilleard, C. and Higgs, P. 200o. Cultures of Ageing: Self, Citizen and the Body. Prentice Hall, Harlow, UK.

Gilleard, C. and Higgs, P. 2011 . Ageing abjection and embodiment in the fourth age. Journal of Aging Studies, 25, 2, $135^{-42 .}$

Gullette, M. 2004. Aged by Culture. University of Chicago Press, Chicago.

Hepworth, M. 2003. Ageing bodies: aged by culture. In Coupland, J. and Gwyn, R. (eds), Discourse, the Body and Identity. Palgrave Macmillan, Basingstoke, UK, 89-1o6.

Hey, V. 20o6. The politics of performative resignification: translating Judith Butler's theoretical discourse and its potential for a sociology of education. British Journal of Sociology of Education, 27, 4, 439-57. 


\section{Bridget Garnham}

Heyes, C. 2007. Self-transformations: Foucault, Ethics, and Normalised Bodies. Oxford University Press, New York.

Heyes, C. 2009. Identity Politics. The Stanford Encylopedia of Philosophy (Spring 2009 Edition) Retrieved 29 July, 2010, from http:/ / plato.stanford.edu/archives/ spr2009/entries/identity-politics/

Higgs, P. 1999. Quality of life and changing parameters of old age. Ageing Ev Mental Health, 3, 3, 197-8.

Higgs, P., Leontowitsch, M., Stevenson, F. and Rees Jones, I. 20og. Not just old and sick - the 'will to health' in later life. Ageing $\mathcal{E}$ ' Society, 29, 687-707.

Hurd Clarke, L. and Griffin, M. 2007. The body natural and the body unnatural: beauty work and aging. Journal of Aging Studies, 21, 187-201.

Hurd Clarke, L. and Korotchenko, A. 2010. Shades of grey: to dye or not to dye one's hair in later life. Ageing $\mathcal{E}^{\circ}$ Society, 3o, 6, $1011-26$.

Hurd Clarke, L., Repta, R. and Griffin, M. 2007. Non-surgical cosmetic procedures: older women's perceptions and experiences. Journal of Women Eं Aging, 19, 3/4, $69-87$.

Jones, M. 2008. Skintight: An Anatomy of Cosmetic Surgery. Berg, Oxford.

Katz, S. 1996. Disciplining Old Age: The Formation of Gerontological Knowlege. The University Press of Virginia, Charlottesville, Virginia.

Katz, S. 2005. Cultural Aging: Life Course, Lifestyle, and Senior Worlds. Broadview Press, Toronto.

Katz, S. and Laliberte-Rudman, D. 2005. Exemplars of retirement: identity and agency between lifestyle and social movement. In Cultural Aging: Life Course, Lifestyle, and Senior Worlds. Broadview Press, Toronto, 140-6o.

Katz, S. and Marshall, B. 2003. New sex for old: lifestyle, consumerism, and the ethics of aging well. Journal of Aging Studies, 1 7, 3-16.

Kvale, S. 1996. InterViews: An Introduction to Qualitative Research Interviewing. Sage, Thousand Oaks, California.

Lloyd, M. 1996. A feminist mapping of Foucauldian politics. In Hekman, S. J. (ed.), Feminist Interpretations of Michel Foucault. The Pennsylvania State University Press, University Park, Pennsylvania, 241-64.

Morse, J. M. 1995. The significance of saturation. Qualitative Health Research, 5, 2, 147-9.

Patton, M. Q. 2002. Qualitative Research Ev Evaluation Methods. Sage, Thousand Oaks, California.

Pitts-Taylor, V. 2007. Surgery Junkies: Wellness and Pathology in Cosmetic Culture. Rutgers University Press, New Brunswick, New Jersey.

Pitts-Taylor, V. 2009. Becoming/being a cosmetic surgery patient: semantic instability and the intersubjective self. Studies in Gender and Sexuality, 10, 3, 1 19-28.

Powell, J. L. 2006. Social Theory and Aging. Rowman \& Littlefield, Lanham, Maryland.

Probyn, E. 1993. Sexing the Self: Gendered Positions in Cultural Studies. Routledge, London.

Probyn, E. 2008. Silences behind the mantra: critiquing feminist fat. Feminism $\mathcal{E}^{2}$ Psychology, 18, 3, 401-4.

Rabinow, P. 2003. Anthropos Today: Reflections on Modern Equipment. Princeton University Press, Princeton, New Jersey.

Richardson, L. and St. Pierre, E. 2005. Writing: a method of inquiry. In Denzin, N. and Lincoln, Y. (eds), The Sage Handbook of Qualitative Research. Sage, Thousand Oaks, California, 959-78.

Smith, F., Wainwright, E., Buckingham, S. and Marandet, E. 2011 . Women, work-life balance and quality of life: case studies from the United Kingdom and Republic of Ireland. Gender, Place $\mathcal{E}$ Culture, 18, 5, 603-10. 
Tulle-Winton, E. 200o. Old bodies. In Hancock, P., Hughes, B., Jagger, E., Paterson, K., Russell, R., Tulle-Winton, E. and Tyler, M. (eds), The Body, Culture and Society: An Introduction. Open University Press, Buckingham, UK, 64-83.

Tulle, E. 2008. The Ageing Body and the Ontology of Ageing: Athletic Competence in Later Life. Body E् Society, 14, 1, 1-19.

Twigg, J. 2004. The body, gender, and age: feminist insights in social gerontology. Journal of Aging Studies, 18, 59-73.

Twigg, J. 2007. Clothing, age and the body: a critical review. Ageing Ev Society, 27, $285^{-305}$.

Warren, C. A. B. 1998. Aging and identity in premodern times. Research on Aging, 2o, $1,11-35$.

Weiss, D. and Kukla, R. 2009. The 'natural look': extreme makeovers and the limits of self-fashioning. In Heyes, C. and Jones, M. (eds), Cosmetic Surgery: A Feminist Primer. Ashgate Publishing, Farnham, UK, $117-32$.

Wenger, G. C. 2003. Interviewing older people. In Holstein, J. A. and Gubrium, J. F. (eds), Inside Interviewing: New Lenses, New Concerns. Sage, Thousand Oaks, California, 111 1-130.

Accepted I9 February 2013 ; first published online 2 April 2013

Address for correspondence:

Bridget Garnham, School of Psychology, Social Work and Social Policy, University of South Australia, Adelaide, Australia.

E-mail: Bridget.Garnham@unisa.edu.au 